\title{
PRODUÇÃO DE $\beta$-GALACTOSIDASE POR BACTÉRIAS ÁCIDO LÁTICAS UTILIZANDO SORO DE LEITE
}

\author{
E. C. da SILVA ${ }^{1}$, P. D. SANTOS ${ }^{1}$, G. A. A. FERNANDES ${ }^{2}$, A. M. O. MOTA ${ }^{3}$, A. L. F. PORTO ${ }^{4}$ e
} M. T. H. CAVALCANTI ${ }^{4}$

${ }^{1}$ Universidade Federal Rural de Pernambuco, Graduandas em Ciências Biológicas, Departamento de Biologia;

${ }^{2}$ Universidade Federal Rural de Pernambuco, Doutoranda em Biociência Animal, Departamento de Morfologia e Fisiologia Animal;

${ }^{3}$ Universidade Federal Rural de Pernambuco, Pós-Doutor Departamento de Morfologia e Fisiologia Animal;

${ }^{4}$ Universidade Federal Rural de Pernambuco, Departamento de Morfologia e Fisiologia Animal E-mail para contato: mtcvsoares@yahoo.com.br

RESUMO - A $\beta$-galactosidase é considerada uma enzima de grande valor para a indústria alimentícia, principalmente pela produção de alimentos sem lactose e com melhores características organolépticas. $\mathrm{O}$ objetivo deste estudo foi selecionar bactérias ácido láticas autóctonas da região Agreste de Pernambuco produtoras de $\beta$-galactosidase utilizando soro de leite como substrato. As bactérias foram reativadas em MRS, cultura estática por $48 \mathrm{~h}$ na temperatura de isolamento de cada micro-organismo e depois $10 \%$ da cultura foi inoculada em soro de leite nas mesmas condições descritas para a reativação. Os melhores resultados foram observados frente à atividade de $\beta$-galactosidase neutra e extracelular. As bactérias do gênero Streptococcus foram as mais promissoras, onde a melhor produtora foi a BAL $\mathrm{n}^{\circ} 182$ com produção de $8,5 \mathrm{U} / \mathrm{mL}$. Pode-se concluir que BAL e o soro de leite possuem um potencial para aplicação industrial.

\section{INTRODUÇÃO}

As bactérias ácido-láticas produzem uma variedade de enzimas importantes, entre elas está a $\beta$-galactosidade, enzima responsável pela hidrolise da lactose, o açúcar do leite, em glicose e galactose, e por isso tem importância na indústria de alimentos lácteos (El Demerdash et al., 2006, Ustok, et al., 2010).

A solubilidade e o poder edulcorante da lactose são baixos quando comparados com outros açucares, como glicose, frutose, galactose e sacarose. Por isso a hidrólise da lactose diminui a precipitação de açúcar e aumenta o sabor doce, assim expandindo as aplicações da solução de lactose nos alimentos (Oliveira et al., 2013).

Além disso, o valor nutricional da lactose é limitado devido à grande proporção de pessoas ao redor do mundo com a falta da enzima $\beta$-galactosidade no trato gastrointestinal e por isso não 
podem utilizá-la, causando uma síndrome conhecida como intolerância a lactose (Vasiljevic \& Jelen, 2002). Isso demonstra o grande valor de mercado que esta enzima possui.

O estudo da produção da enzima $\beta$-galactosidase a partir do soro de leite torna-se uma alternativa interessante, uma vez que o soro é reconhecido pela rica composição nutricional que permite uma série de aplicações na indústria alimentícia, e por se trata de um subproduto de elevado rendimento, uma vez que para produzir $1 \mathrm{Kg}$ de queijo, como o queijo de Coalho, necessita-se de $10 \mathrm{~L}$ de leite bovino em média, o que resulta em torno de $9 \mathrm{~L}$ de soro (Richards, 2002), com isso o soro do leite pode ser visto sob dois aspectos bem distintos: agente de poluição, se descartado inadequadamente (Guven et al., 2008). E como atualmente a legislação ambiental está mais rígida, as indústrias de laticínios procuram alternativas para aproveitamento desse subproduto (Florêncio et al., 2013).

Assim, o objetivo deste trabalho foi produzir $\beta$-galactosidase utilizando bactérias ácido láticas cultivadas em soro de leite para aplicação em alimentos lácteos visando aumentar a digestibilidade dos produtos.

\section{MATERIAIS E MÉTODOS}

\subsection{Micro-organismos}

As bactérias utilizadas neste estudo pertencem ao acervo de bactérias ácido láticas isoladas de queijo de Coalho artesanal do Estado de Pernambuco de propriedade do Laboratório de Tecnologia de Bioativos (LABTECBIO) da Universidade Federal Rural de Pernambuco (UFRPE). Foram escolhidas aleatoriamente 30 bactérias, sendo 10 de cada gênero: Enterococcus, Streptococcus e Lactobacillus.

\subsection{Produção de $\beta$-galactosidase}

As bactérias ácido láticas foram reativadas três vezes em MRS caldo (Man, Rogosa \& Sharpe, 1960) em cultura estática, na temperatura de isolamento de cada cultura sendo $30 \pm 1{ }^{\circ} \mathrm{C}$ ou $37 \pm 1{ }^{\circ} \mathrm{C}$, com intervalo de $48 \mathrm{~h}$ entre as reativações. Em seguida, $10 \%$ (v/v) das culturas foram inoculadas em soro de leite bovino obtido a partir da fabricação do queijo de Coalho artesanal, e incubadas nas mesmas condições da reativação. Após esse período, as culturas foram centrifugadas a $10.192 \mathrm{xg}$ por 5 minutos a $4{ }^{\circ} \mathrm{C}$, e o sobrenadante extracelular foi congelado e armazenado para análises futuras.

A massa celular precipitada durante a centrifugação foi ressuspendida em $5 \mathrm{~mL}$ de água estéril e submetida a tratamento para obtenção do material intracelular através da lise celular por ultrassom (Ultrasonic Clean - Unique $1600 \mathrm{~A}$ ) por 30 minutos a $4{ }^{\circ} \mathrm{C}$, com posterior centrifugação realizada nas condições anteriormente mencionadas. $O$ sobrenadante obtido a partir da massa celular foi congelado para a avaliação da produção de $\beta$-galactosidase intracelular. 


\section{9 a 22 de outubro de 2014 \\ Florianópolis/SC}

\subsection{Determinação da atividade de $\beta$-galactosidase}

Foi realizada segundo os procedimentos descritos no Food Chemical Codex (National Academy of Sciences, 2005). O substrato cromogênico o-nitrofenil- $\beta$-D-galactopiranosídeo (ONPG - Sigma) foi dissolvido em tampão fosfato de sódio 0,05 M. A quantidade de substrato e enzimas utilizados foi $2 \mathrm{~mL}$ e $0,5 \mathrm{~mL}$, respectivamente. No tempo zero, 0,5 $\mathrm{mL}$ da solução enzimática foi adicionada à solução de ONPG e incubada por $15 \mathrm{~min}$. O ensaio foi parado com adição de $0,5 \mathrm{~mL}$ de carbonato de sódio a $10 \%$ e a absorbância determinada a $420 \mathrm{~nm}$. Uma unidade foi definida como a quantidade de enzima que liberou $1 \mathrm{mM}$ do o-nitrofenol do ONPG por minuto sob as condições deste ensaio. Todos os experimentos foram realizados em duplicata.

\section{RESULTADOS E DISCUSSÃO}

Os resultados estão apresentados nas Figuras 1, 2 e 3, respectivamente para os gêneros Enterococcus, Streptococcus e Lactobacillus.

Podemos observar em todas as Figuras que a atividade de $\beta$-galactosidase classificada pela metodologia como neutra foi a mais promissora, alcançando níveis de atividade de 1,3 a 8,5 $\mathrm{U} / \mathrm{mL}$, sendo a primeira obtida pela dosagem da enzima intracelular e a segunda na enzima extracelular.

Em relação ao tipo de enzima, em todos os gêneros a $\beta$-galactosidase extracelular mostrou as maiores atividades com valores de 2,1 a $8,5 \mathrm{U} / \mathrm{mL}$, sendo a primeira obtida para a mostra 82 de Lactobacillus e a segunda para a amostra 182 de Streptococcus. Entretanto, uma amostra de Lactobacillus apresentou 5,4 U/mL de atividade intracelular de $\beta$-galactosidase.

Sendo assim, a partir dos nossos resultados é possível inferir que as bactérias ácido láticas produzem a enzima $\beta$-galactosidase, confirmando os resultados obtidos por Vinderola e Reinhmeir, (2003), que trabalharam com bactérias ácido láticas dos gêneros Streptococcus, Lactobacillus e Lactococcus, eles também observaram a produção enzimática em espécies de Streptococcus e Lactobacillus. Entretanto, os citados autores encontraram que os Lactobacillus foram os maiores produtores de $\beta$-galactosidase intracelular, o que diverge dos resultados aqui apresentados.

A habilidade em produzir $\beta$-galactosidase também foi observada em Bifidobacteria por Hsu et al.(2005). Esses autores estudaram a produção da enzima variando a composição do meio, e encontraram uma atividade enzimática intracelular média de $4,9 \mathrm{U} / \mathrm{mL}$ em um meio considerado por eles como padrão. Valor superior ao observado nos nossos estudos em relação à atividade intracelular, mas abaixo do encontrado para enzima extracelular.

Em outro estudo com bactérias ácido láticas, Zárate e Chaia (2012), estudaram a produção de $\beta$-galactosidase em Propionibacterium acidipropionici utilizando um meio sintético, as atividades apresentadas por estes autores foram abaixo dos resultados observados para os nossos experimentos.

A utilização do soro como substrato também se mostrou promissor, esse fato é relevante para mais um tipo de utilização desse subproduto da cadeia produtiva do leite, agora com um aspecto mais biotecnológico. 


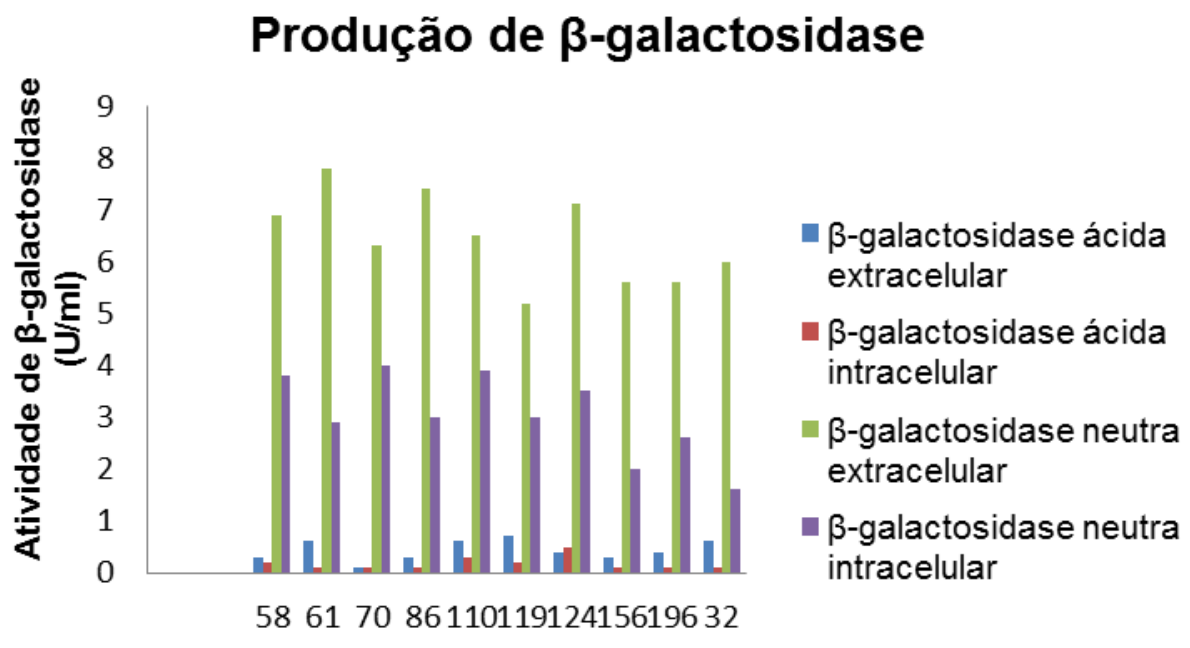

Amostras de Enterococcus

Figura 1. Resultados obtidos com a produção da $\beta$-galactosidase em soro de leite por amostras de Enterococcus isolados de queijo de Coalho artesanal de PE.

\section{Produção de $\beta$-galactosidase}

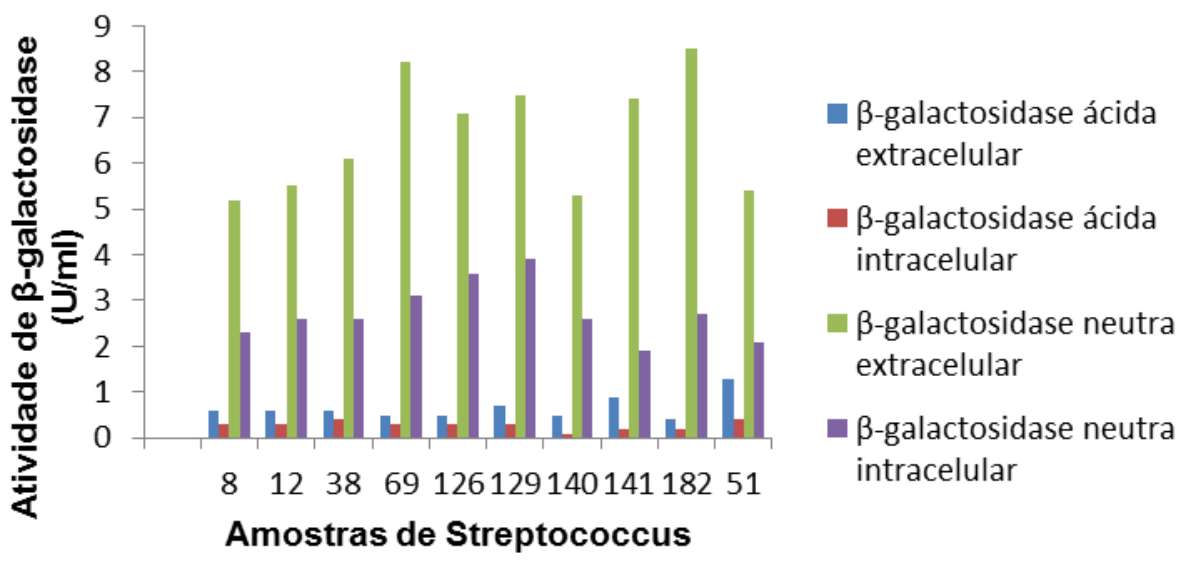

Figura 2. Resultados obtidos com a produção da $\beta$-galactosidase em soro de leite por amostras de Streptococcus isolados de queijo de Coalho artesanal de PE. 


\section{Produção de $\beta$-galactosidase}

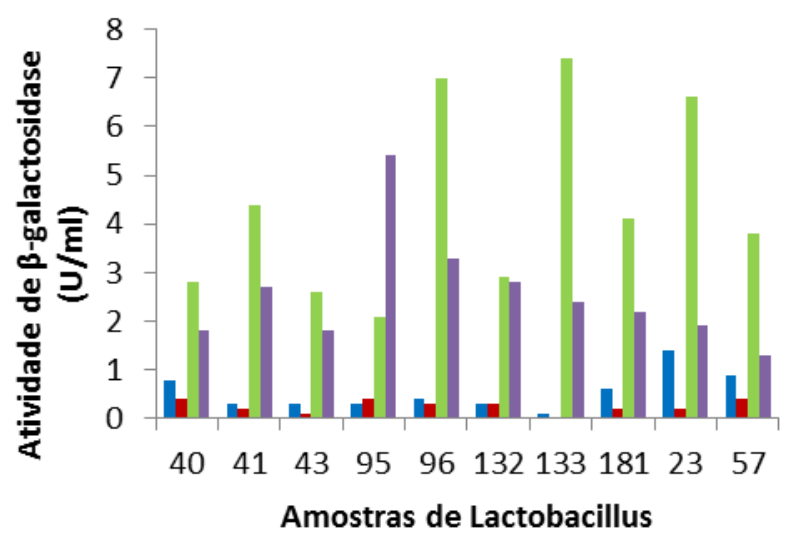

$\beta$-galactosidase ácida Extracelular

- $\beta$-galactosidase ácida Intracelular

- $\beta$-galactosidase neutra Extracelular

- $\beta$-galactosidase neutra Intracelular

Figura 3. Resultados obtidos com a produção da $\beta$-galactosidase em soro de leite por amostras de Lactobacillus isolados de queijo de Coalho artesanal de PE.

\section{CONCLUSÃO}

A produção de $\beta$-galactosidase por bactérias ácido láticas isoladas de queijo de Coalho artesanal em soro de leite bovino se mostrou viável, tendo como maior produtora nas condições testadas neste estudo uma amostra de Streptococcus .

\section{REFERÊNCIAS}

EL DEMERDASH, H.A.; OXMAN, J.; HELLER, K.J.; GEIS, A. Yoghurt fermentation at elevated temperatures by strains of Streptococcus thermophilus expressing a small heat-shock protein: application of a two-plasmid system for constructing food grade strains of Streptococcus thermophilus. Biotech J., v. 1, p. 398-404, 2006.

FLORÊNCIO, I.M.; FLORENTINO, E.R,; SILVA, F.L.H.; MARTINS, R.S.; CAVALCANTI, M.T.; GOMES, J.P. Produção de etanol a partir de lactossoro industrial. Rev. Bras. Eng. Agríc. Amb., v.17, p.1088-1092, 2013.

GUVEN, G.; PERENDECI, A.; TANYOLAC, A. Electrochemical treatment of deproteinated whey wastewater and optimization of treatment conditions with response surface methodology. J.Hazard. Mater., v. 157, Issue 1, p. 69-78, 2008.

HSU,C.A; YU,R.C; CHOU,C.C. Chou Production of h-galactosidase by Bifidobacteria as influenced by various culture conditions. Int.J.Food Microbiol.,v. 104, p.197-206 ,2005. 
MAN,J.C.; ROGOSA, M.;SHARPE, M.E. A medium for the cultivation of lactobacilli. J. Appl. Bacterol., v. 23, p. 130-135, 1960.

National Academy of Sciences (2005) Food Chemicals Codex - Committee on Food Chemicals Codex, Food and Nutrition, $5^{\circ}$ ed. Washington, DC, USA.

RICHARDS, N.P. Soro lácteo; perspectivas industriais e proteção ao meio ambiente. Food Ingred., v. 17, p.20-24, 2002.

USTOK, F.I; TARI, C; HARSA, S. Biochemical and thermal properties of $\beta$-galactosidase enzymes produced by artisanal yoghurt cultures. Food chem., v.119, p.1114-1120, 2010.

VASILJEVIC, T.; JELEN, P. Production of $\beta$-galactosidase for lactose hydrolysis in milk and dairy products using thermophilic lactic acid bacteria. Innov.Food Sci Emer.Tech., v. 2, p. 75-85, 2001.

VINDEROLA,C.G; REINHEIMER,J.A. Lactic acid starter and probiotic bacteria: a comparative "in vitro" study of probiotic characteristics and biological barrier resistance. Food Res.Int., v.36, p.895-904,2003.

ZÁRATE, G.;CHAIA,A.P. Influence of lactose and lactate on growth and $\beta$-galactosidase activity of potential probiotic Propionibacterium acidipropionici. Anaerobe., v.18, p.25-30, 2012. 